\title{
Reconstructing Deformation History by Using Microstructural and Petrographic Analysis of Sorobo, Konso Area, Southern Ethiopia
}

\author{
Muluken Fanta Bassa \\ Department of Geology, Arbaminch University, Arbaminch, Ethiopia \\ Email address: \\ Mulukenfanta2009@gmail.com \\ To cite this article: \\ Muluken Fanta Bassa. Reconstructing Deformation History by Using Microstructural and Petrographic Analysis of Sorobo, Konso Area, \\ Southern Ethiopia. International Journal of Environmental Monitoring and Analysis. Vol. 8, No. 5, 2020, pp. 130-143. \\ doi: $10.11648 /$ j.ijema.20200805.12
}

Received: March 10, 2020; Accepted: May 25, 2020; Published: September 21, 2020

\begin{abstract}
The deformation history of Sorobo, Konso area (southern Ethiopia) within the Mozambique Belt, is described using microstructural and petrographic analysis. The area is characterized by folds and metamorphic fabrics that trend between NNE and NNW and consist of high-grade, amphibolite- to granulite-facies rocks. It is affected by five deformational phases (D1 to D5) and two metamorphic events (M1 \& M2). During shortening deformation events (D1 to D3) the development of gneissosity (D1), the formation of tight to isoclinal and recumbent folds (D2) and the superposition of secondary (upright) fold (D3) on earlier recumbent fold resulting in type-3-fold interference pattern are formed respectively. During fourth deformation phase (D4) most of the rock units of the area are affected by shearing or shows east and west vergence. The area is affected by both sinistral and a dextral sense of shearing but dextral shear-sense appears dominant. Brittle type of deformation phase (D5) was developed and resulting in different types of faults varies in orientation. Peak progressive metamorphism of the granulite facies (M1) and retrogression (M2) are also associated with the deformational phase. An equal-area plot and rose diagram shows the orientation of all fabric, which indicates multiphase deformation. Geological structures in the study areas like faults, joints \& fissures, shear zones and folds are important depositional sites for different hydrothermal economic mineral deposits.
\end{abstract}

Keywords: Microstructure, Deformation, Metamorphism, Progression, Retrogression

\section{Introduction}

Microstructural analysis describes the textural features of the rock, and can provide information on the conditions of formation, petrogenesis, and subsequent deformation, folding or alteration events. The study of metamorphic rock microstructures aims to determine the timing, sequence and conditions of deformations, mineral growth and overprinting of subsequent deformation events. A microstructural and metamorphic study of a naturally deformed rock provides evidence of behavior of earth during progressive deformation. Therefore, this study concerns the reconstruction of deformation history of Konso area, southern Ethiopia within East Africa orogeny (EAO).

Pan-African Orogeny is a tectonic, magmatic and metamorphic activity that took place in Neoproterozoic to early Paleozoic age [7]. Pan African tectono-thermal activity in the Mozambique Belt was broadly contemporaneous with magmatism, metamorphism and deformation in the ArabianNubian Shield. The difference in lithology and metamorphic grade between the two belts has been attributed to the difference in the level of exposure, with the Mozambican rocks interpreted as lower crustal equivalents of the juvenile rocks in the Arabian - Nubian Shield [8].

The concentrations of granulitic rocks in the Mozambique Belt and their absence from the Arabian-Nubian Shield support the interpretation that crustal thickening, erosion, and intensity of deformation increase to the south. EAO has been proposed for the combined upper crustal Arabian - Nubian shield in the north and lower Mozambique Belt in the south comprising mostly pre - Neoproterozoic crust with a Neoproterozoic - early Cambrian tectono-thermal overprint. The Mozambique belt defines the southern part of the EAO and essentially consists of medium to high - grade gneisses 
and voluminous granitoids. The Mozambique Belt is a Neoproterozoic, polycyclic, collisional belt that extends along and underlies the eastern margin of much of the African continent [12]. It is characterized by folds and metamorphic fabrics that trend between NNE and NNW and consists of high-grade, amphibolite- to granulite-facies rocks [5] forming a gneissic migmatitic complex. In Ethiopia, the $\mathrm{MB}$ is exposed in the south and south-west and forms a front with the ANS, a lower grade (greenschist facies) calcalkaline volcano-sedimentary terrain to the north (Figure 1).

Southern Ethiopia is underlain by Neoproterozoic - early Paleozoic rocks, which were formed and/or deformed during the EAO associated with collision between East and West Gondwana [13] after the closure of the Mozambique ocean $[11 ; 15]$. Older rocks, late Archean to paleoproterozoic granitoid gneisses, strongly reworked during the Pan African orogenic cycle and locally migmatized and/or mylonitized during Pan - African events or are separate crustal entities (exotic blocks) of unknown origin [7].

There are three major divisions (Lower, Middle and Upper Complexes) in the Mozambique Belt of southern Ethiopia that have been differentiated by characteristic contrasts in structural style, lithology and metamorphism [6].

Samuel [10] suggested that the Archean rock with E - W foliation trend that are considered as craton by the earlier workers are not craton, but the rocks represent a Proterozoic supracrustal sequence.
According to [4], the Precambrian metamorphic rocks show variation in composition, structural style, degree of metamorphism and texture. Based on the above parameters the rocks are classified in to high grade and low-grade metamorphic rocks. Interlayered gneiss and granitic gneiss represent the high-grade rocks. The interlayered gneiss is represented by biotite - quartz - feldspar gneiss, hornblende gneiss, biotite gneiss, marble and biotite - muscovite gneiss rock types. The low-grade rock consists of only metabasalt. Therefore, a systematic and comparative petrological, geochemical, geochronological and structural study of granites from both the ANS and the MB in Ethiopia appears to be crucial to understand the geodynamic evolution of these terrains and their relationships. This contribution dealing with the MB is part of an integrated study of the late- to post tectonic granitic magmatism in both the ANS [2] and the $\mathrm{MB}$.

The Precambrian crystalline basement of Ethiopia is of particular interest because it contains almost all known mineral commodities of the country (both industrial and metallic minerals), notably gold, platinum, rare metals, kaolin, feldspar, clay, asbestos, talc, nickel, copper, iron, chromium, etc. Marble, limestone and granite are also common [14].

A pluton in the MB of southern Ethiopia which is the Konso pluton (Figure 1) was regarded as a Pan-African posttectonic body [3].

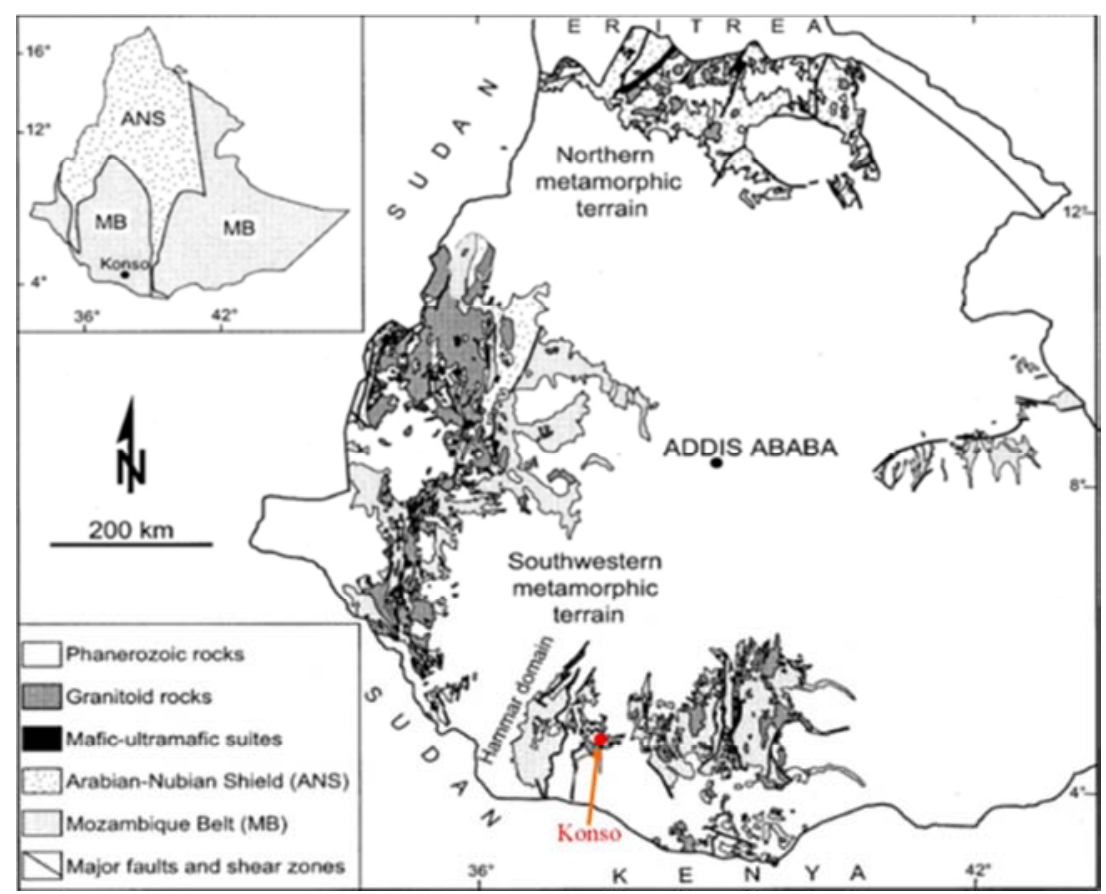

Figure 1. Simplified geological map of the metamorphic terrains of Ethiopia that shows the distribution of the ANS and the MB rocks [1].

\section{Description of the Study Area}

Konso area is located at about $595 \mathrm{~km}$ south of Addis Ababa, $362 \mathrm{~km} \mathrm{SW}$ from Hawasa, $150 \mathrm{~km}$ E from Jinka and $110 \mathrm{~km}$ NW from Yavello in the South Nation Nationality and people regional state, Ethiopia. The specific study area is about $17 \mathrm{~km}$ far from the town of Konso, Karat in the NW direction. It is bounded between 594000-599000N and 0320000-0324000E UTM reading covering $20 \mathrm{~km}^{2}$. The Konso area covers between minimum elevations $501 \mathrm{~m}$ to maximum elevation up to $2000 \mathrm{~m}$ above mean sea level at Baticara Mountain. It is 


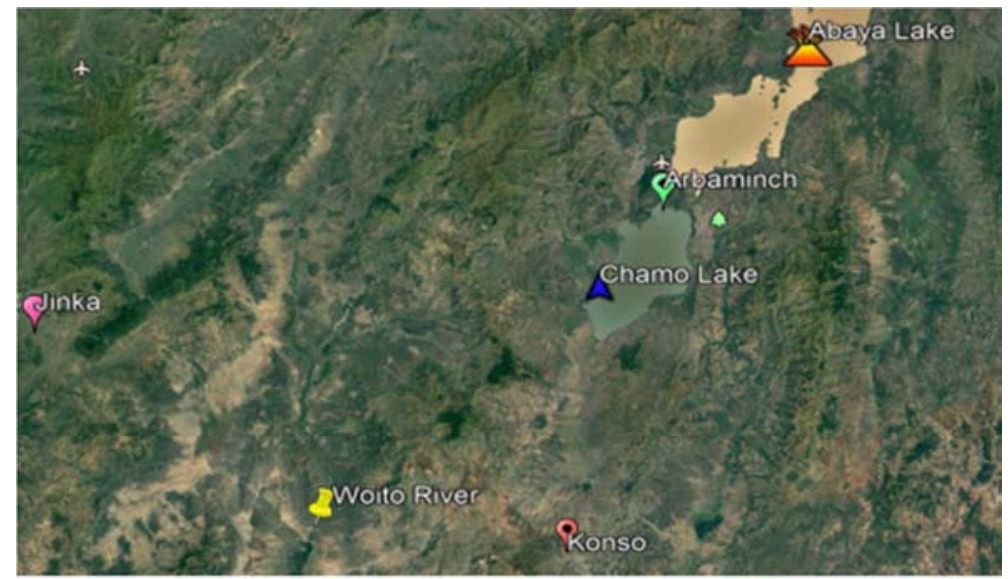

Figure 2. Physiography and location of the study area.

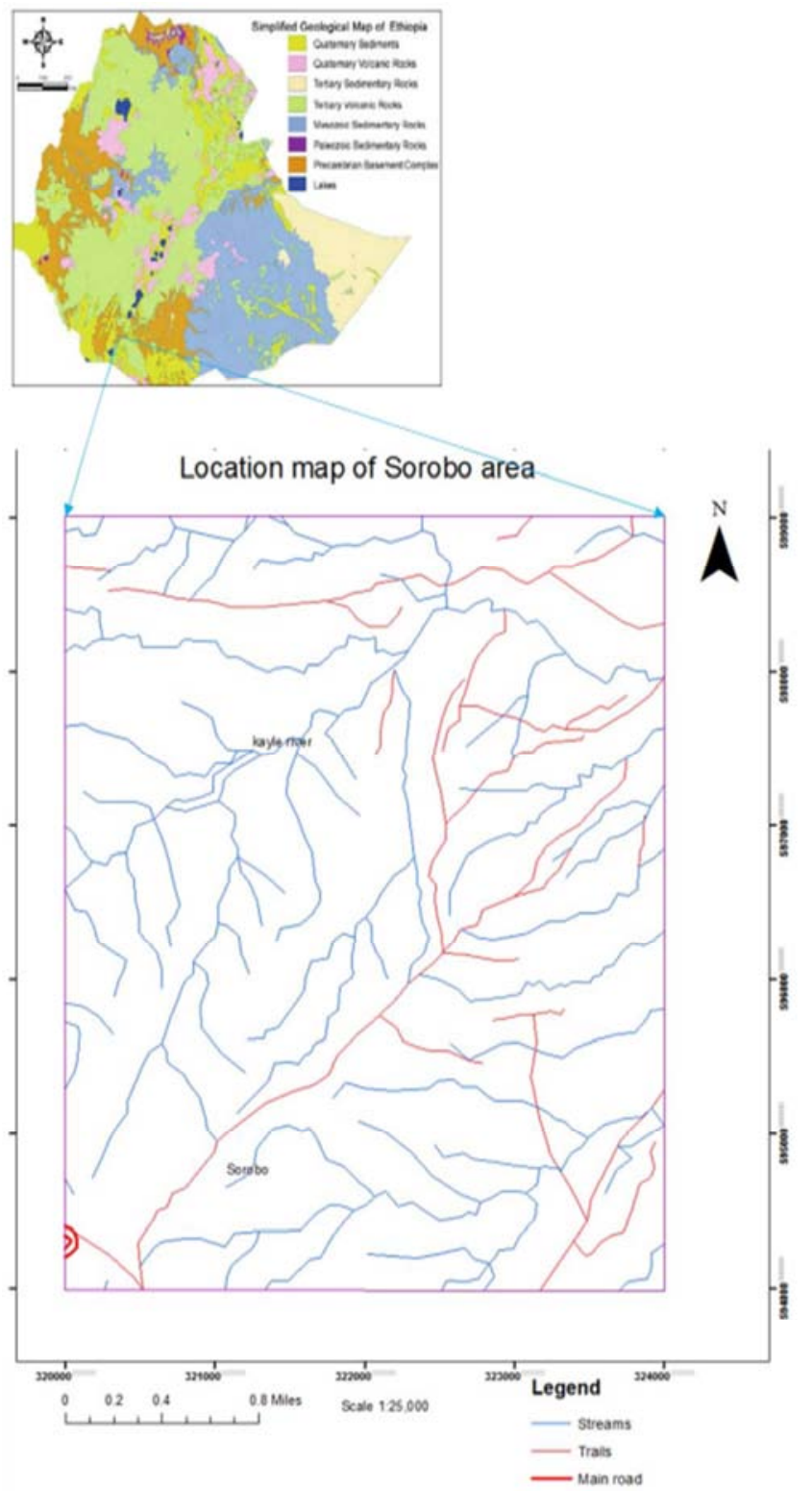

Figure 3. Location map of the study Sorobo area.

\section{Methodology}

To achieve the above objectives the following methods and approaches were used:

Different available information about the area and previous works are gathered, this includes reading and organizing published and unpublished reports on geology, analyzing topographic, geological and structural maps of the area at a scale of 1:50,000 and 1:25,000 and also interpreting satellite images of an area.

Preliminary field work / road geology/ was conducted around Konso area of southern Ethiopia. During the main field season, different traverse lines were selected across the geology following river routes. In each traverse, many stations are taken along the traverse line at different places.

To construct the geological and structural map, a systematic record of structural features and lithology has been done, with a special emphasis on the earlier nature of the rocks. Field data is well organized and compiled and a geological and structural map at a scale of 1:25,000 is produced using ArcGIS (version 10.3) software. The timing of transformation of various minerals with respect to specific deformation and metamorphic events is established based on microstructural and petrographic analysis. Stereoplots (equalarea projection and rose diagram) of the orientation of the main fabric elements was done, which are important to ease understanding of the orientation of several geological structures on two-dimension.

\section{Result}

The study area is largely covered by metamorphic rocks which have undergone medium to high grade of metamorphism and are exposed mostly along the stream cut. The rocks include amphibole gneiss, granulite, granitic gneiss and amphibolite. There are also different geological structures in the study area like: dikes, different type of veins, fault, joints, foliation and lineation. Based on fieldwork a geological and structural map of the area was prepared in $1: 25,000$ scale. 


\subsection{Lithological Description}

\subsubsection{Granulite}

Granulite is a medium- to coarse-grained, non-foliated metamorphic rock with a granoblastic texture (approximately equi-granular) and gneissose to massive structure. It is composed of mainly clinopyroxene, plagioclase, hornblende, quartz and accessory garnet minerals.

In outcrop level the granulite is visually quite distinct with abundant small pink or red garnets in a granular matrix as shown in Figure 4. The minerals, as seen in a thin-section, occur as small rounded grains forming a closely fitted mosaic (Figure 5). They are somewhat sub-rounded found in between the larger grains of quartz and feldspar. The presence of clinopyroxene (early crystallized) mineral in a rock unit indicates a high temperature of crystallization with lack of water. The harder and older granulite rock is exposed to the surface when the overlying gneisses rock eroded. The temperature and pressure fall due to uplift when the overlying rock eroded and the formation of hornblende from clinopyroxene are an indication for retrogression in the area. The mineral assemblage of this rock unit with granular textural features indicates the granulite facies metamorphism.

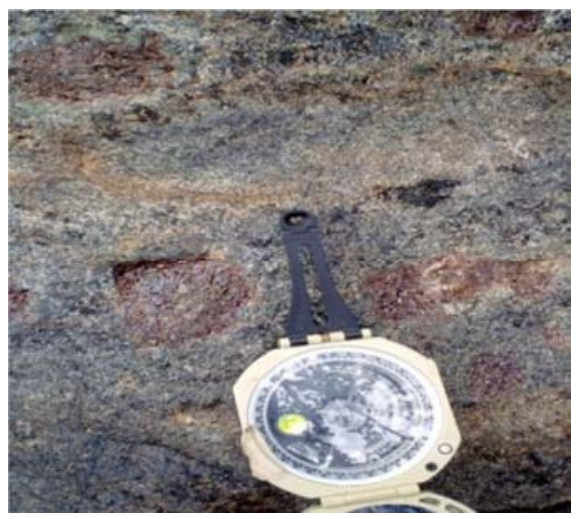

Figure 4. Garnet-bearing granulite from Sorobo area; serpentine mineral surrounds around garnet at the top left.
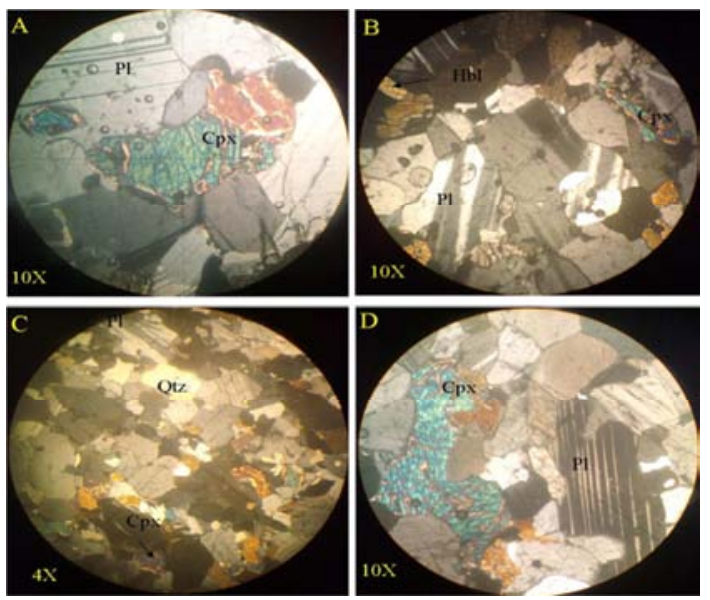

Figure 5. Microphotograph of granulite rock in thin section; A) xenoblastic plagioclase and clinopyroxene minerals $B$ and $C$ ) formation of hornblende from clinopyroxene due temperature drop and plagioclase with fluid inclusion D) plagioclase crystal shows a distinct banding effect of polysynthetic twinning in the rock unit, all are under XPL.

\subsubsection{Amphibolite}

The amphibolite is dark and non-foliated metamorphic rock and characterized by medium- to coarse- grain size (Figure 6). It is exposed at the stream cut and covers a small portion of the study area. Hornblende, plagioclase, quartz, +/clinopyroxene, +/- biotite and +/- chlorite are the main constituents of this rock unit (Figure 7). The mineral assemblage of this rock unit indicates the upper amphibolite facies metamorphism. This rock shows spheroidal weathering (pills like skin of an onion) as the result of chemical weathering of systematically jointed, massive rocks (Figure $6 \mathrm{C}$ ). The differences in weathering rates between the corners, edges, and faces of a bedrock block will result in the formation of spheroidal layers of altered rock that surround a rounded boulder-size core of relatively unaltered rock.
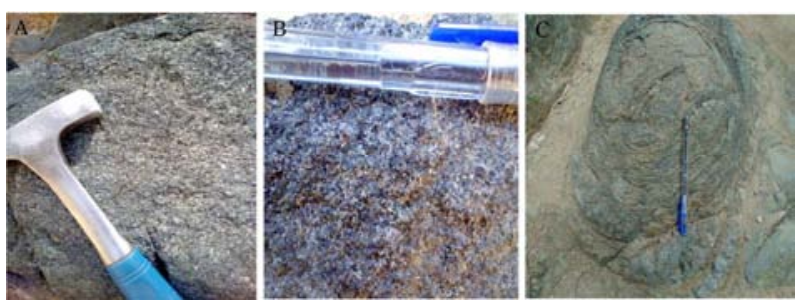

Figure 6. Photographs taken from the study area shows $A \& B$ ) Amphibolite rock in outcrop level exposed at the SW and SE of the study area. C) Spheroidal type of weathering in amphibolite rock.
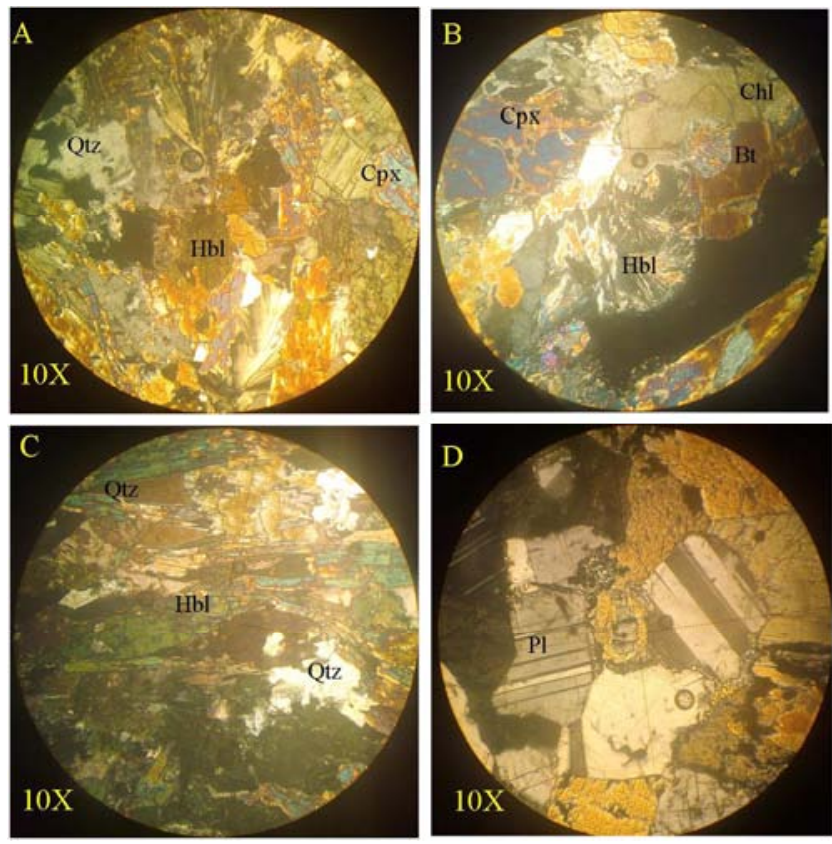

Figure 7. Microphotograph of mineral grain in amphibolite rock unit in thin sections; A) Hornblende mineral at extinction position, B) chlorite mineral is retrogradically formed from biotite, C) laths of hornblende contains quartz inclusion and D) plagioclase.

\subsubsection{Interlayered Gneiss}

This unit is well foliated, representing alternating layers composed of mafic and felsic minerals (Figures 8 and 10). There are two varieties of interlayered gneiss, amphibole gneiss and granitic gneiss.

(i). Amphibole Gneiss 
This rock unit covers the largest area from that of amphibolite and granitic gneiss. In hand specimen, the rock is medium- to -coarse grained (high grade) and shows gneissose fabric and in some places dissected with quartzofeldspathic veins. Dark bands typically dominated by hornblende of quartz and feldspar were observed in hand specimens. In addition to the gneissose fabric; mafic and felsic dikes, quartz veins and pegmatites are common structures in this rock unit. Generally, this rock unit is composed of hornblende, plagioclase feldspar, and quartz with trace amount of biotite and opaque minerals. Besides, tourmaline mineral is found as accessory minerals.
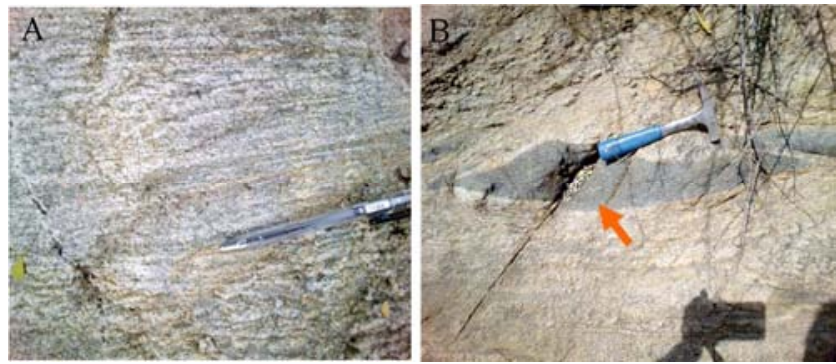

Figure 8. A) Field Photograph of amphibole gneiss rock clearly showing foliation. B) Weakly deformed xenoliths of amphibole within amphibole gneiss rock.
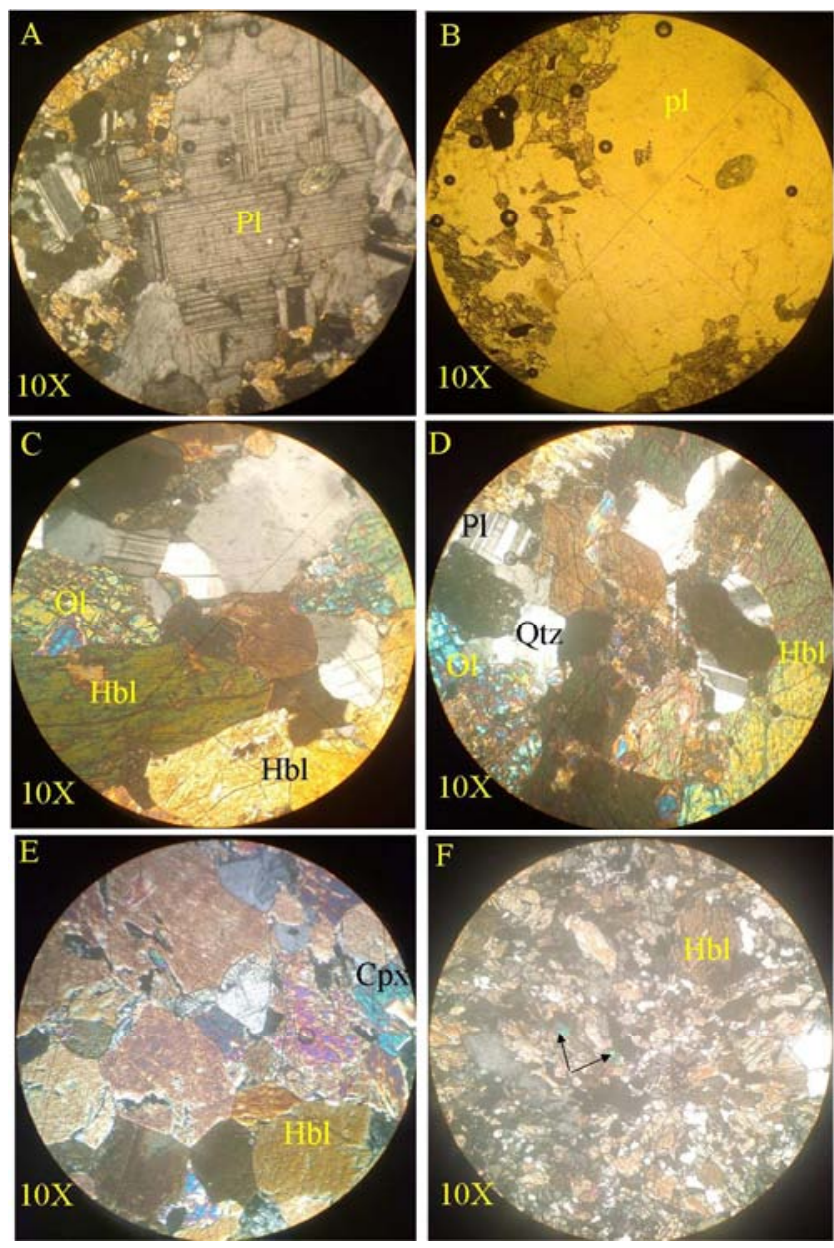

Figure 9. Microphotograph of mineral grains in amphibole gneiss rock in thin section: all are under XPL except $B, B$ in $P P L$.

\section{(ii). Granitic Gneiss}

Granitic gneiss is medium- to -coarse grained rock and covers a small area with respect to the other units of the mapped area. It is intimately intercalated with amphibole gneiss, well foliated and locally banded. Plagioclase, quartz, hornblende, biotite and +/- clinopyroxene are the main constituents of this rock unit. Banding is defined by segregation of felsic (quartz and feldspar) and mafic (biotite and hornblende) minerals. Plagioclase feldspar is characterized by elongated and foliated fabric and is a major component of the rock.

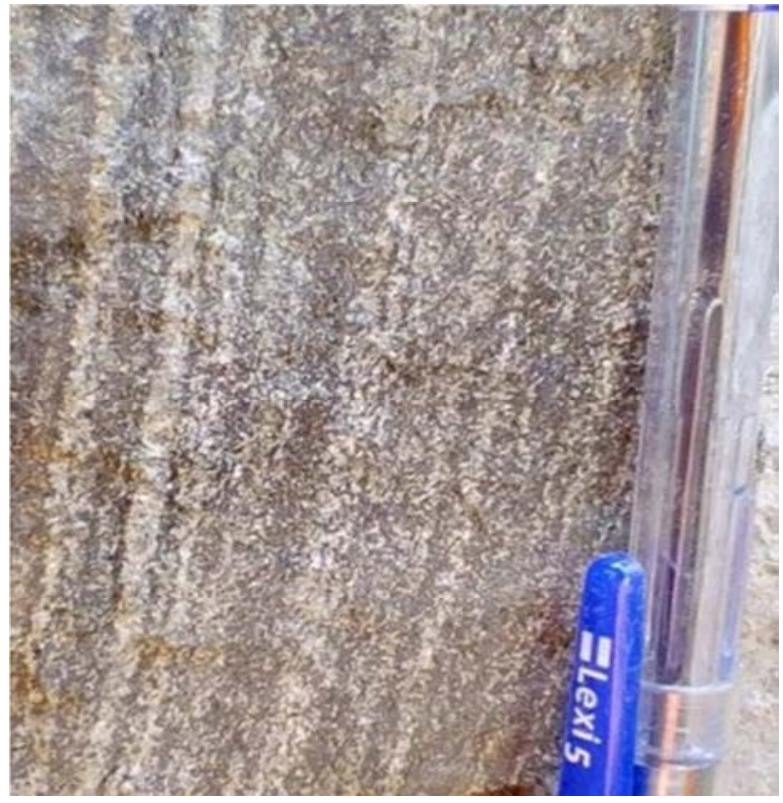

Figure 10. Field photograph of granitic gneiss rock in outcrop level exposed at the $S W$ of the study Sorobo area.

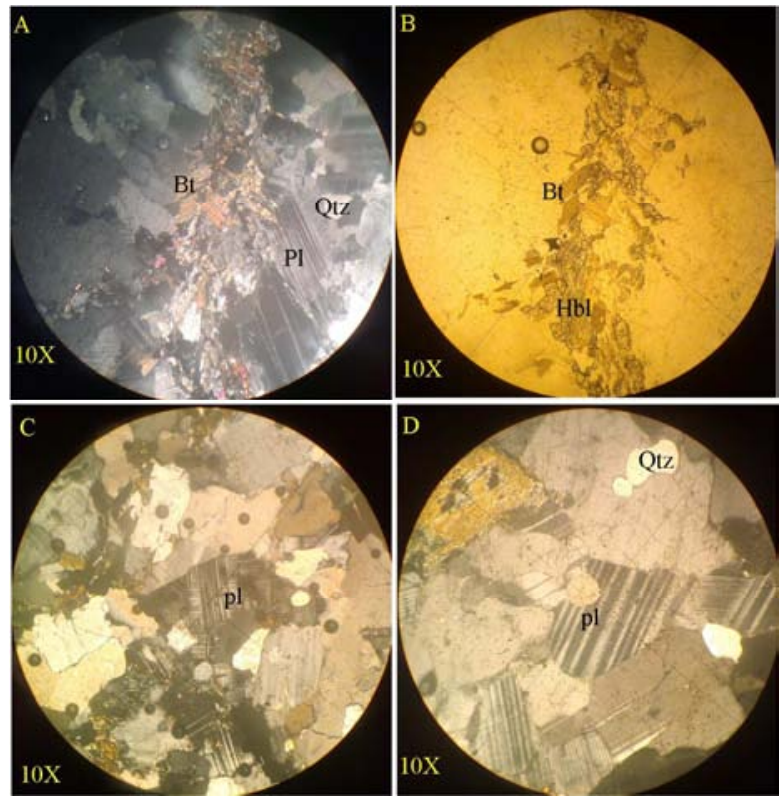

Figure 11. Microphotograph of mineral grains in granitic gneiss rock in thin section; $A$ and B) shows polysynthetic twinning in plagioclase, C) shows crosshatched twinning in plagioclase, D) shows deformation and growth twinning in plagioclase; all are under XPL except $B$. 


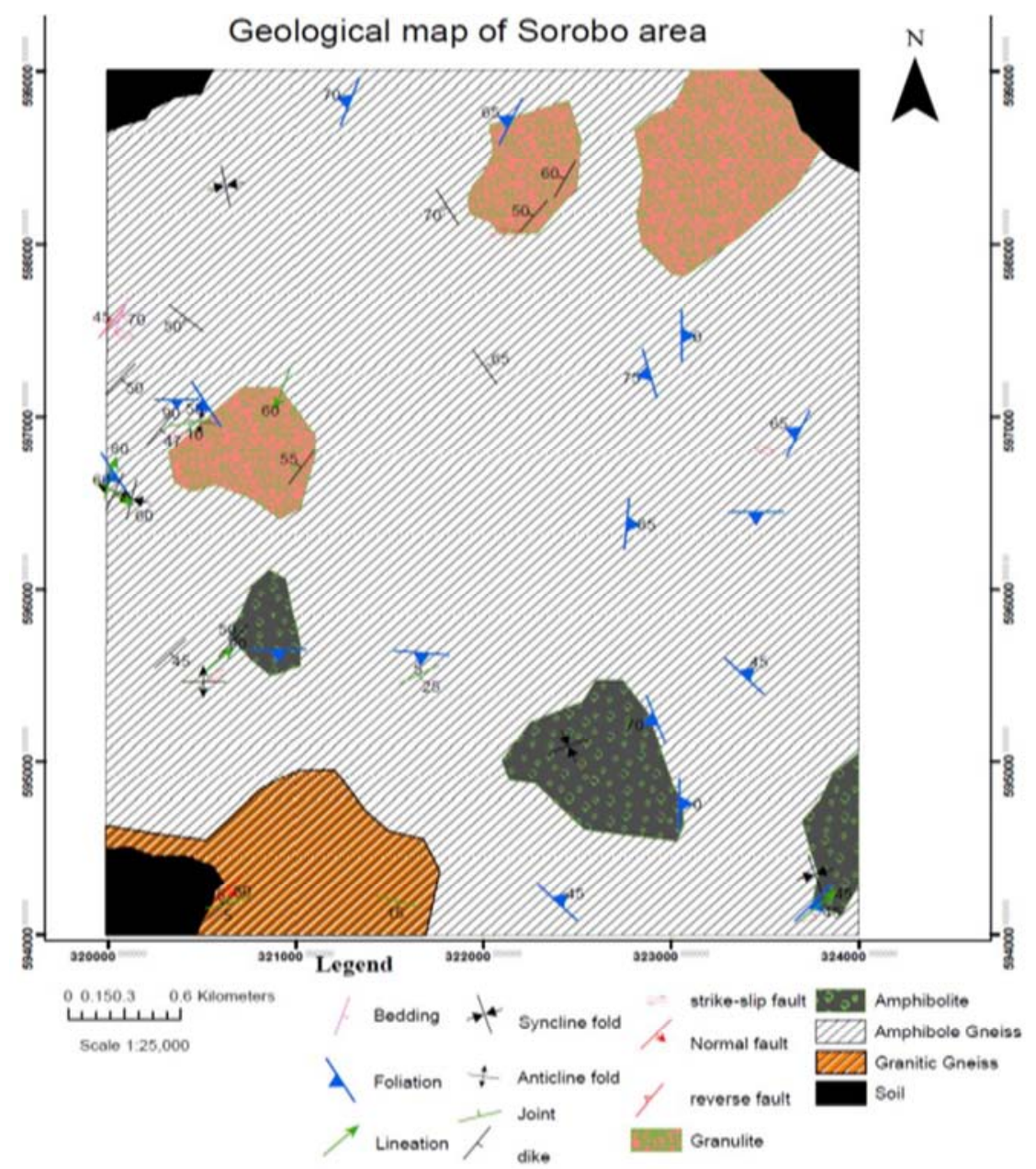

Figure 12. Geological and structural map of the study Sorobo area.

\subsection{Geological Structure}

There are both brittle and ductile geological structures and tectonic processes are responsible for the many discontinuity planes resulted in different geologic micro- to macrostructures. Foliation, lineation, fold, fault, joint, dike, veins and veinlet's and other microstructures are the major deformational structures in the area.

\subsubsection{Mesoscopic Geological Structures}

\section{i. Foliation}

Foliation is a planar structure in a metamorphic rock resulting from the ductile flattening of grain aggregates (plagioclase and quartz) and mica. Figure 13A shows gneissic banding formed from tectonic segregation of mafic and felsic minerals, which are formed prior to folding. The first phase of deformation (D1) was formed due to northwest - southeast compressional stress and resulting west - east trending foliations in the study area. Folding of gneissose fabric resulted during the second deformation phase (D2) (Figure 13B).

There are ductile shear sense indicators in the study are which are characterized by showing different vergence directions. These veregence directions are indications for D4 deformation phases which show east and west vergence direction in the area (Figure 15). This is resulted from sinistral (left-lateral) and dextral (right lateral) shearing. The general trend and plunge of lineation are $045^{\circ} / 40^{\circ} \mathrm{SE}$. Foliation appears to be axial planar to a minor fold with very much longer westerly dipping than easterly dipping limbs but, shows the general SW, SE, NW and NE dipping attitudes.
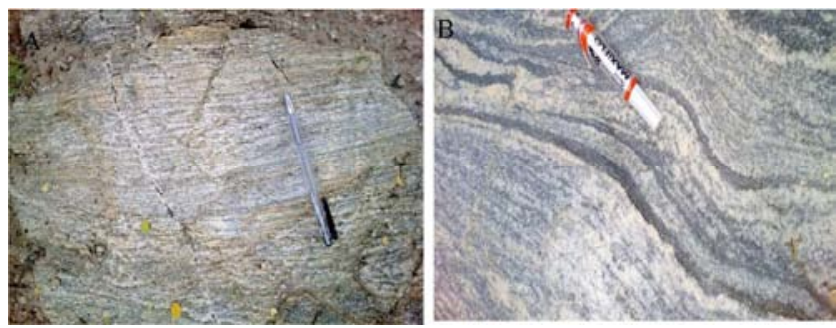

Figure 13. Field photograph show A) Gneissosity formed from segregation of mafic and felsic minerals resulted during D1 and B) Folding of gneissose fabric develops gentle fold resulted during the second deformation phase (D2).

\section{ii. Fold}

There are many fold structures like: symmetrical, asymmetric (east and west verging folds), anticline, syncline and recumbent folds are a major minor fold structures present 
in the area.

There are parasitic folds in which hinge zones and limbs of large folds often display folds of smaller wavelength and amplitude where the F1 (earlier fold) hinge lines are deformed to bend over F2 (later fold), the sense of asymmetry of earlier (F1) parasitic folds develop on adjoining limbs of F2 (Figure 16). They are indicative of the axial traces of the major folds, which has parallel fold axes to the major fold axes. The orientation of parasitic (secondorder fold) structures is representative of the orientation of the large or regional (first-order) structures. The sense of asymmetry is consistently towards the hinges of second-order antiforms.

It varies systematically across the axial surfaces of the first-order folds. The presence of parasitic folds is a manifestation of two generations of folding in the area. However, the sense of rotation of the parasitic folds reveals the presence of an overturned syncline fold with axial trace trending and plunge 130/40SW (Figure 16). The sense of asymmetry of different folds depends up on the sense of shear strain parallel to the verging surface. Ptygmatitic folds are also found in the area, which involves an irregularly folded, isolated layer, typically a quartzo-feldspathic vein in amphibolite rock unit. This structure has rounded and nearparallel, commonly concentric folds in which the amplitude is large and the wavelength small with respect to the almost constant layer (vein) thickness (Figure 14D).

Some folds have a continuous axial plane (harmonic fold) across successive folded layers that show approximately the same wavelength and amplitude. Others show discontinuous axial plane along folded layers (disharmonic) in which the amplitude, wavelength and style change along discontinuous axial surfaces from one layer to another. These disharmonic folds develop because of different rheology in the different layers. The incompetent beds are squeezed and adopt to the form imposed by the competent beds.

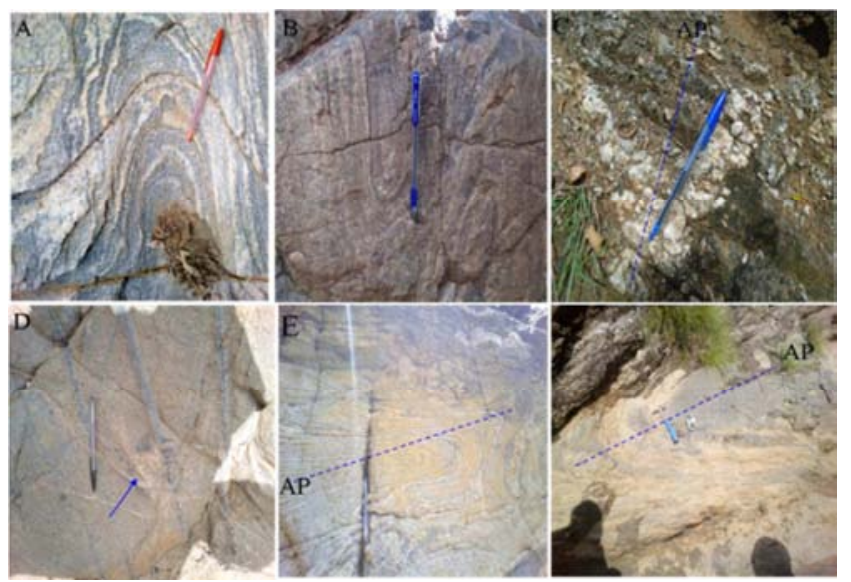

Figure 14. Fold photographs taken from the field; A) Anticline fold, B) Syncline fold which have a vertical axial plane, C) Symmetric folds with straight limbs, sharp angular hinges and have acute inter-limb angles of angular fold, D) the arrow shows irregularly folded ptygmatic fold, and $E \&$ $F)$ recumbent fold, which have sub-horizontal axial surface/hinge line resulted during D2, AP in figure is axial plane of folds; Photo taken looking for all NW except angular fold which is looking towards NE.
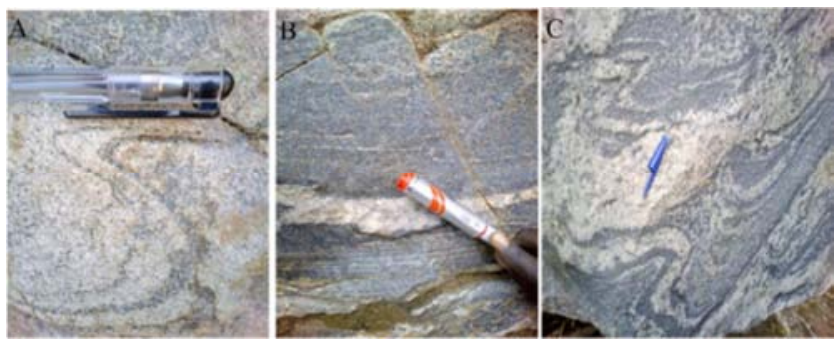

Figure 15. Field photograph shows vergence direction A) west-vergence shows left-lateral (sinistral) shearing; $B$ and $C$ ) East-vergence shows rightlateral (dextral) shearing which shows clockwise rotation; resulted during D4.

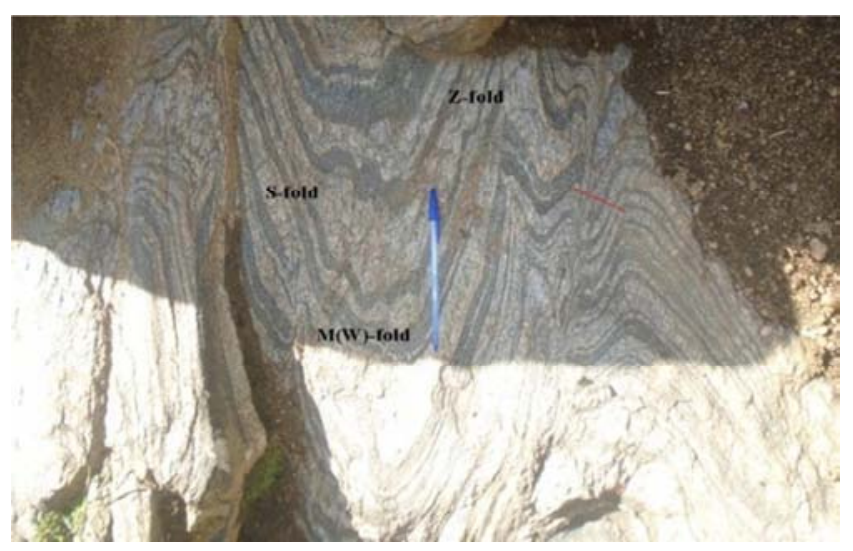

Figure 16. Field photographs of parasitic folds. The sense of rotation is pointing towards synclinal axial trace. The red arrow shows detachment fold which indicates fold transposition, photo taken looking east.

\section{iii. Joint}

Joints are fractures formed without any significant displacement and observed in amphibolite, dike (basaltic dike) and amphibole gneisses units of the study area and resulted during brittle D5 deformation phase. There are different generations of joints in different parts of the area which are parallel or oblique to foliation. The major striking directions of joints measured in the field are SE, NE, SW and NW and the dip amount range from $5^{\circ}$ to $90^{\circ}$ (Figure 17A).

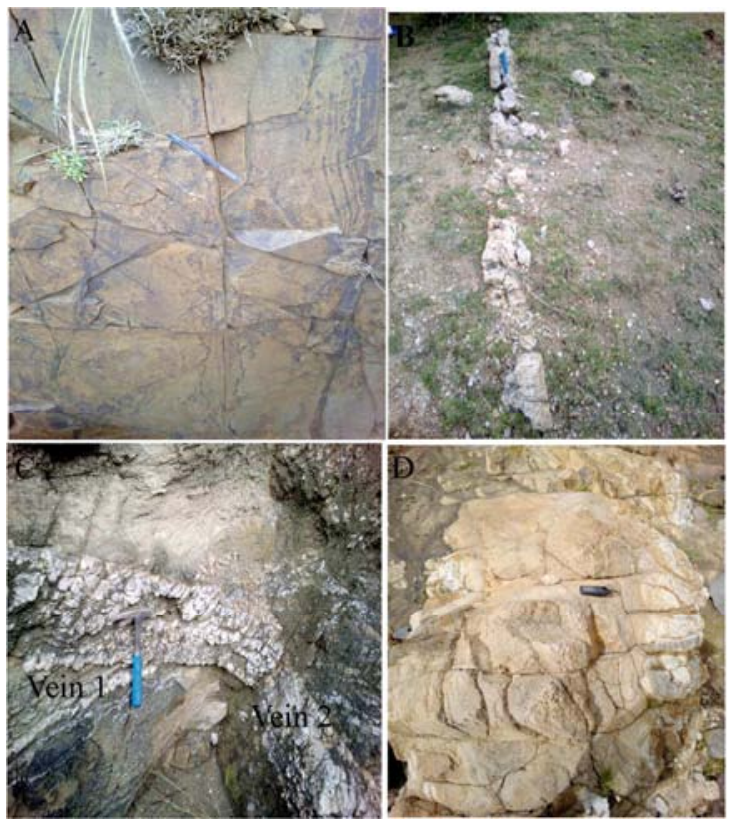




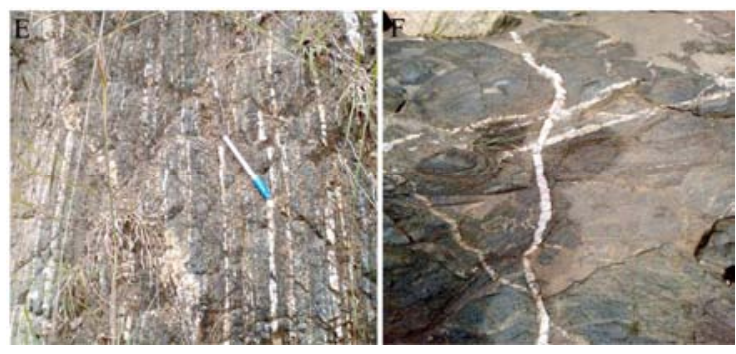

Figure 17. Field photograph shows A) Non-systematic joints, B) Pegmatite Veins, C) Pegmatite Veins are cross-cut to each other. D) felsite dike, E) quartz veins and $F$ ) showing the relative age of veins based on the cross-cut relationship. Photo taken looking A towards SE; B towards NE; C towards $N ; D, E$ and $F$ towards $N W$.

\section{iv. Dikes}

These structures found in the study area are tabular in shape and discordant in orientation with the surrounding rock. Some are mafic in composition (Figure $17 \mathrm{~A}$ ) and some are felsic (felsite) (Figure $17 \mathrm{~B}$ and D) formed when magma intrudes to the country rock. Their average thickness ranges from $20 \mathrm{~cm}$ to $2 \mathrm{~m}$ and have variable length.

v. Veins

Vein/veinlet is sub-planar concentrations of minerals that have precipitated from solution. There are both pegmatite and quartz veins in the area. Pegmatite vein mainly contains medium to coarse grained minerals of quartz, plagioclase, muscovite, and small amount of biotite and accessary garnet. In quartz vein the solubility of silica in aqueous $\left(\mathrm{H}_{2} \mathrm{O}\right.$-rich) solutions decreases dramatically with decreasing temperature, such that quartz dissolves into fluid at high temperature, but then precipitates as the solution cools and becomes supersaturated. They range from 3 centimeter to 2-meter width with various lengths. Both pegmatite and quartz veins are parallel, oblique or perpendicular to the foliation plane.

vi. Boudinage

Boudins form when lengthening affects a layered rock formation involving competent felsic layers (granite/pegmatite intrusion) boudinaged within a less competent, easily deformable, host rock (amphibolite rocks). Extension proceeds without rotation and evolves with symmetric boudins (Figure 18).

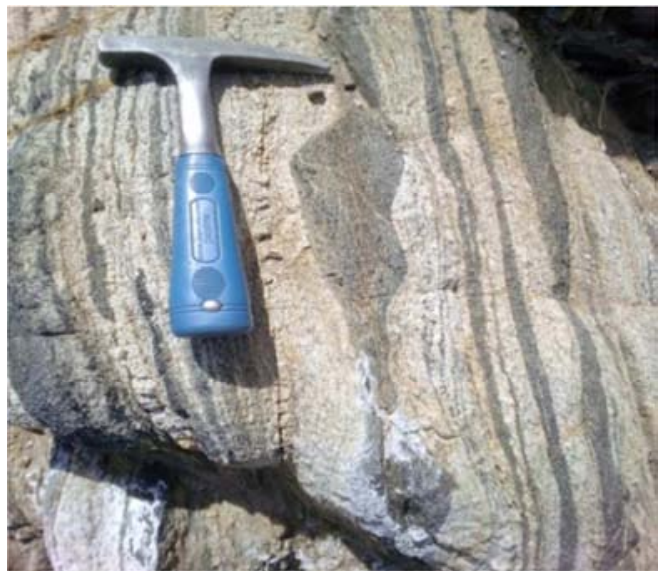

Figure 18. Field photograph show Pinch-and-Swell structures, competent felsic layers boudinaged within a less competent amphibolite rocks.

\section{vii.Faults}

The faults in the study area are minor and micro-faults. This brittle type geological structure resulted following ductile-brittle shear deformation phase (D4) during D5 and has dip amount ranges from $25^{\circ}$ to $90^{\circ}$.

Kamb Contouring method and 1\% Area Contouring method:

These are practiced for a small numbers of data sets. They allow graphic analysis of the statistical significance of point concentrations on an equal-area plot. The observed densities of different fabric element data points have preferred orientation in the area of study.
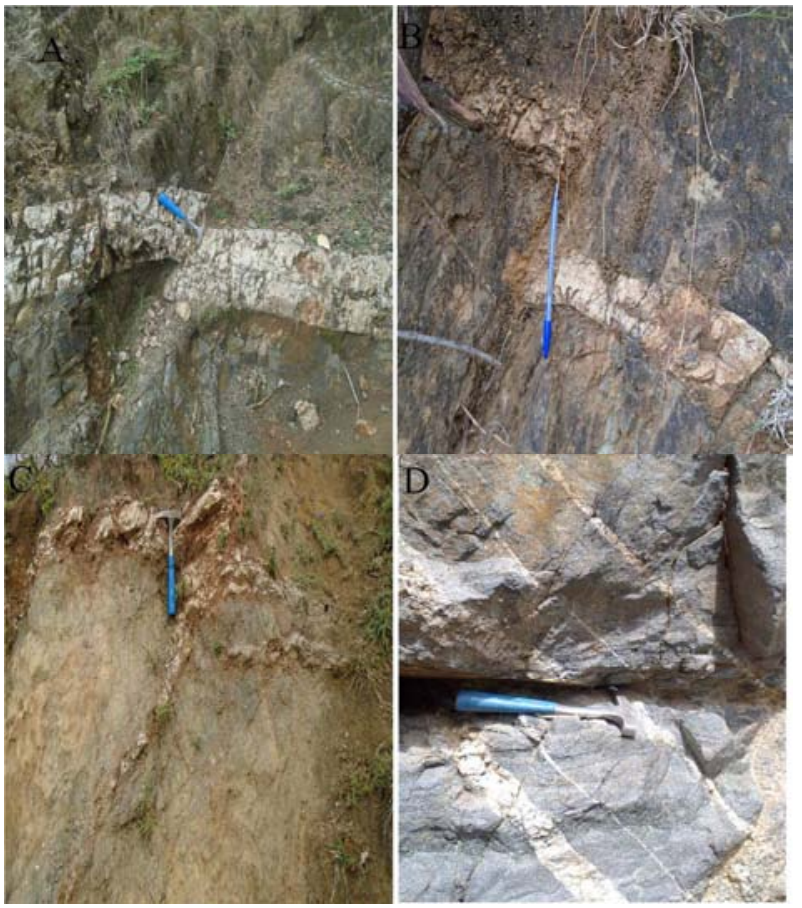

Figure 19. Fault photographs shows; $A, B$, and $C$ shows reverse fault in the study area; D) show right lateral (dextral) strike-slip fault. Photo taken looking A towards East, B, C and D towards North.

\section{Stereographic projection}

The stereographic projection is used to represent 3D orientation data in a 2D graphical form [9].

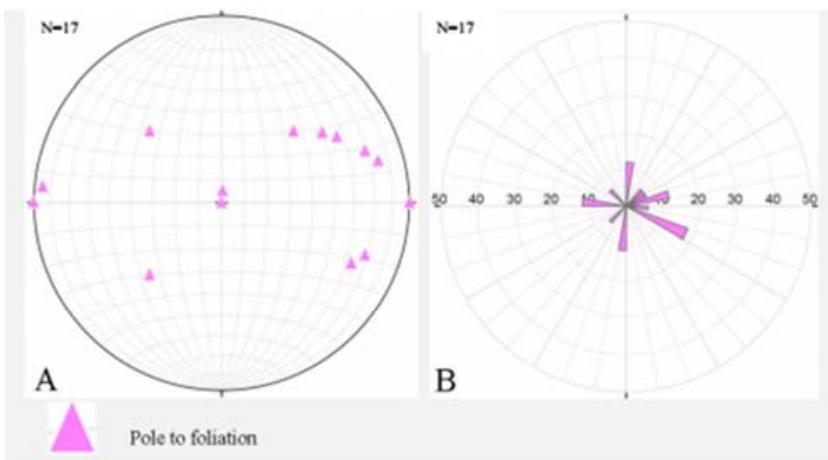

Figure 20. Stereoplots of A) poles to foliation shows the prevalence of moderate westerly dipping and shows the general NW-NE trending orientation and B) Rose diagrams of pole to foliation shows the stress direction of gneissosity formation. This randomly distributed pole to foliation indicates polyphase deformation. 


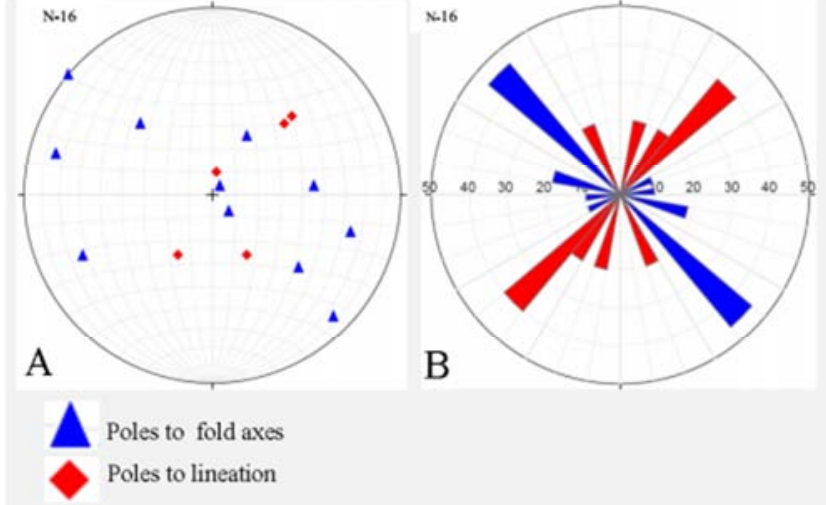

Figure 21. Stereoplots of structural elements from different rock units shows A) northwest and southeast plunging poles to fold axis and southwest and northeast plunging lineation. B) Rose diagram indicating the stress direction of fold axes and lineation.
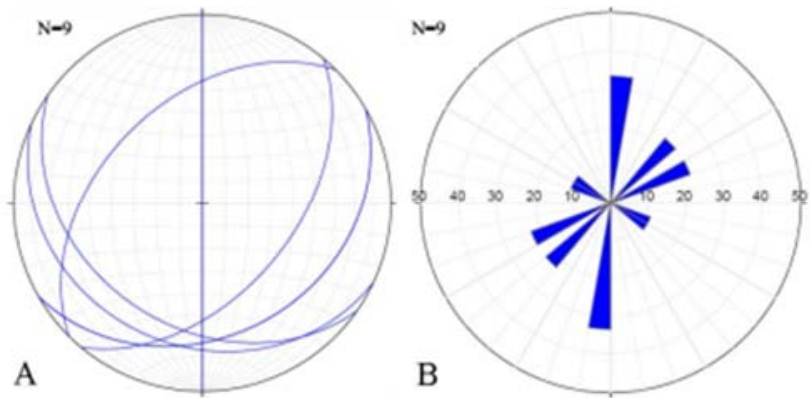

Figure 22. Stereoplots using an equal-area projection for the fault data from different rock units observed in the entire area indicating A) $N E-N W$ trending fault plane and B) rose diagram shows the trend of fault planes.

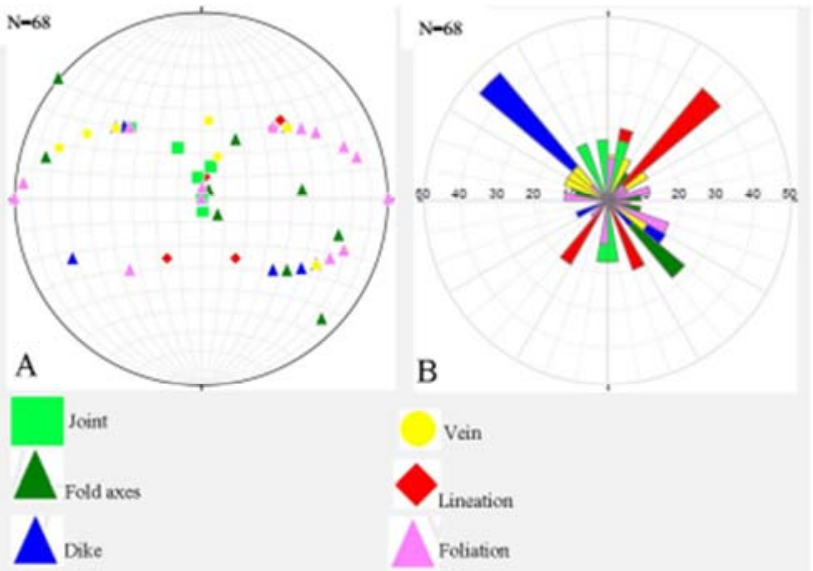

Figure 23. Equal-area projections for the whole data from Sorobo area; A) Stereoplots using an equal-area projection to show the generalized distribution of data points from different rock units observed in the study area. B) The radial histogram in the rose diagram shows the direction of strike; the direction of the strike indicates the direction of the main force of plate tectonics in the area.

By using a contoured equal-area point diagram the orientation of the axial trace of fold is determined from a large number of data points of pole to foliation and pole to fold axes. The high-density region is a $\pi$-maxima and the great circle that passes through $\pi$ maxima is $\pi$-circle and the line perpendicular (pole) to it is $\pi$-axis or axial planar, which show the orientation of fold axes. This contoured $\pi$ - diagram indicates the style of folds. The shape of the girdle /the bands of contours across the diagram/ reflects the shape of the fold. Figure 24 of pole to foliation shows asymmetric fold whose westward-dipping limbs are longer than the eastward-dipping limbs and have NNW trending axial trace. Pole to fold axes in figure 24 also show asymmetric overturned Anticline fold, which fold axes trending NE.
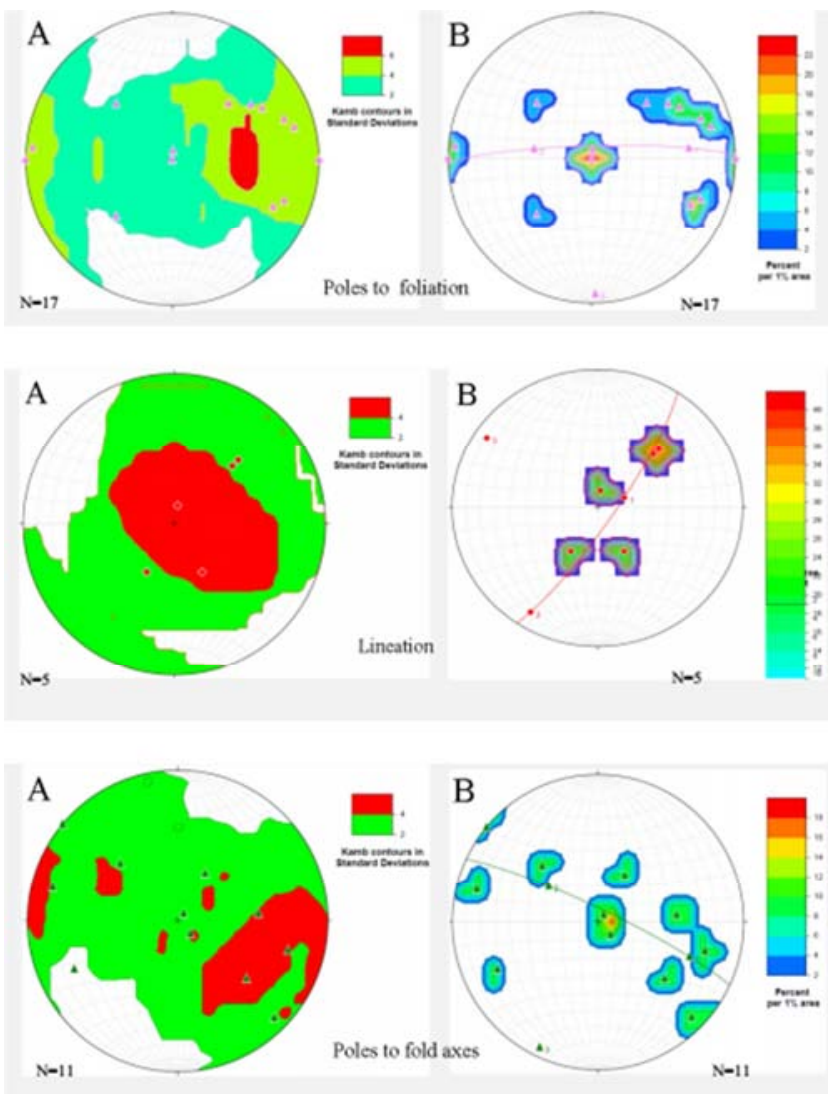

Figure 24. Best fit great circle for different fabric elements using an equalarea projection; (A) Kamb Contouring method. (B) $1 \%$ area Contouring method. The pole to foliation indicates that the rock is folded about a steeply southwest-plunging axis and the fold axes indicate that the rock is folded about $S$-W plunging axis. Generally, all the structures indicate that the rock is folded about $S-W$.

\subsubsection{Microstructures}

(i). Micro-fault

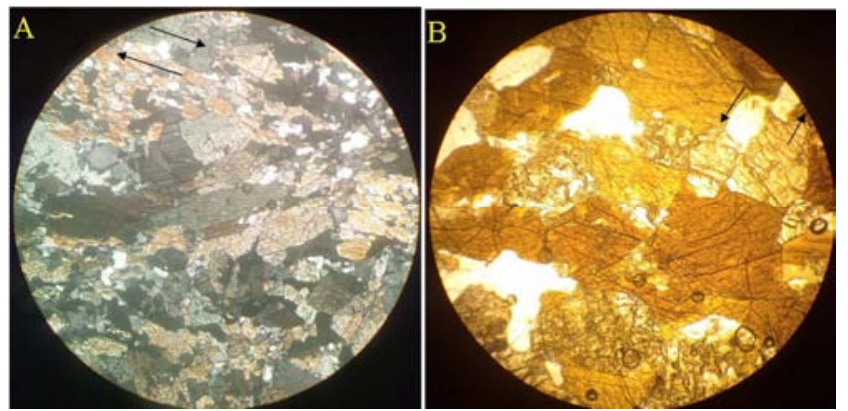

Figure 25. Microphotograph of mineral grain shows micro faults transecting quartz porphroclasts $A$ ) show a dextral sense of shear $B$ ) show sinistral sense of shear. 10X, A under XPL, B under PPL. 
Micro-faults in the study area are shear micro-fractures formed by cataclasis that contain rigid grain fragments. It is a good indicator of brittle shear zones; Figure $25 \mathrm{~A}$ and B show dextral and sinstral sense of shear respectively. Displacement parallel to a micro-fault surface can be identified from displaced grain boundaries or fragments. There is inconsistent sense of offset of a number of grain boundaries at a variety of angles to the micro-crack, this is a useful indication of true shear displacement.
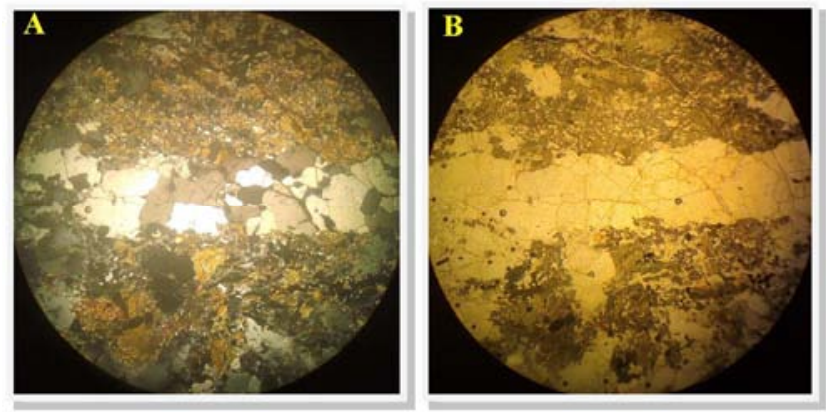

Figure 26. Microphotograph of crack-seal structure; 10X, A under XPL and $B$ under $P P L$.

\section{(ii). Fibrous Veins}

The repeated crack-seal growth is resulted to the formation of fibrous vein; syntaxial fibre veins developed in the study area (Figure 26). These veins involve progressive fibre growth from each wall of the fracture towards the center. The crystals forming the fibres show a close compositional link with the rock through which the vein cuts.

(iii). Deformation Lamellae

Quartz minerals in figure below show intracrystalline deformation or deformed internally without brittle fracturing by movement (Figure 27).
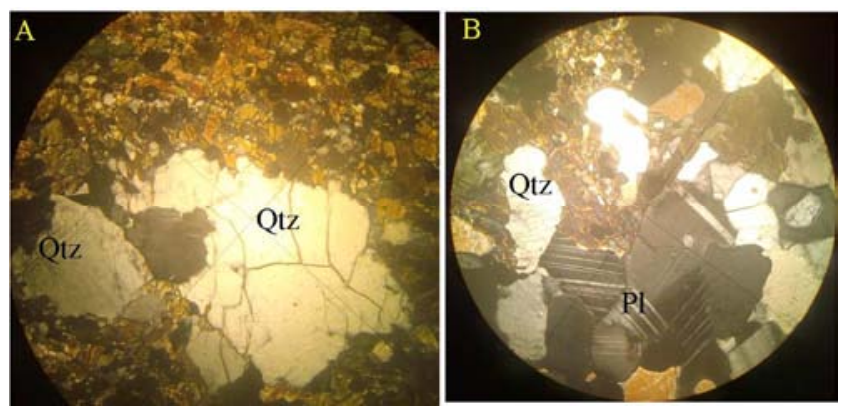

Figure 27. Microphotograph shows deformation lamellae and micro-cracks in quartz; $10 X, X P L$.

\section{(iv). Twinning}

Thin section shows plagioclase mineral is indicative of both deformation twinning (mechanical) and growth twinning. Deformation twin is distinguished from growth twins by its shape; which is tapered towards the crystal center (Figure 7D and 11) and is concentrated at high strain sites where two crystals touch each other or at the rim of the crystal. It does not involve breaking of the crystal lattice, and therefore considered as plastic deformation mechanism.

\subsection{Ductile Shear Sense Indicators}

There are several meso-scales (Figure 28D) and microscale (Figure 28 A, B \& C) ductile shear sense indicator features which is used to determine the sense of shear. These shear sense indicators are asymmetric folds and mica fish. Asymmetric fold shows a fold axis at a high angle to foliation, may indicate the sense of shear. Figure 28D shows the rotation of the fold axial plane from vertical towards right, indicates dextral shear sense.

Large single mineral grains with an elongate sigma shape, consisting of internally undeformed and isolated mineral grain in a relatively fine-grained matrix have been observed from thin section analysis (Figure $28 \mathrm{~A}, \mathrm{~B} \& \mathrm{C}$ ). This type of microstructure form by slip on the flat surfaces of the structure and are thought to remain stable in orientation during ductile deformation. Their orientation is commonly tilted against the general sense of shear and can form a small tail of recrystallized material that can be interpreted the same as sigma-type tails. The geometry of mica fish structure is the result of dissolution, growth and internal deformation. Commonly, trails of small mica fragments extend into the matrix from the tips of isolated mica fish.
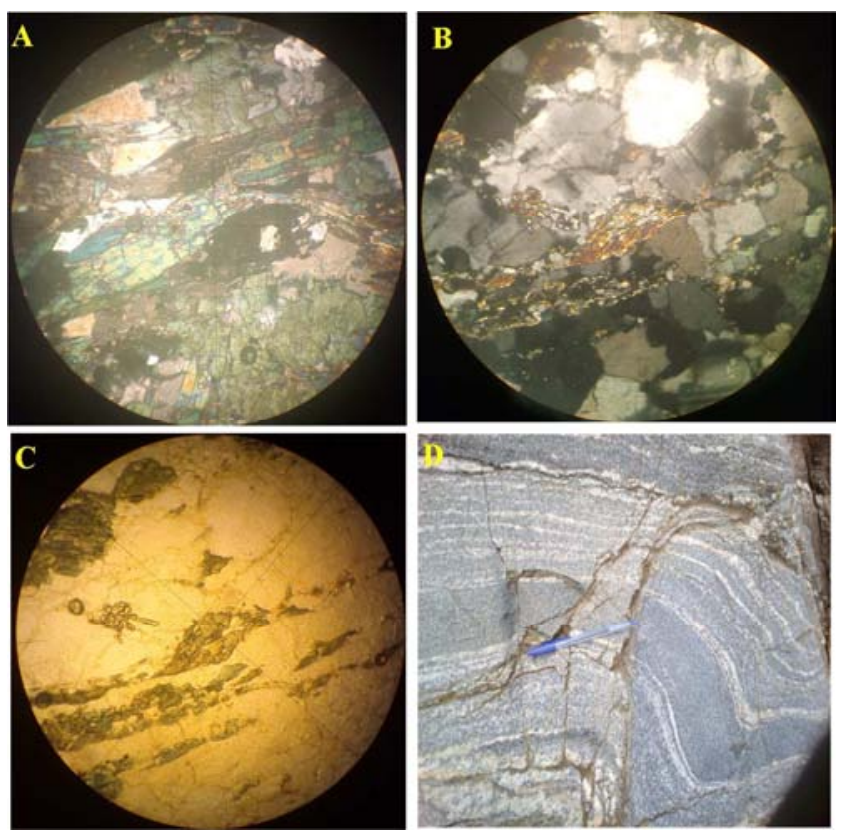

Figure 28. Microphotograph of $A, B$, and $C$ are Mica fish contains a stairstepping of the wings of mica fragments and $D$ is asymmetric fold from the field, indicates a dextral shear sense. The matrix contains quartz mineral which is dynamically recrystallized and developed an oblique foliation; $A$ and $B$ under XPL, C under PPL, $10 X$.

\subsection{Deformation and Metamorphic History}

Deformation and metamorphic history can be distinguished by analysis of minerals and microstructures in metamorphic rocks. By analyzing the sequence in which the minerals and structures were formed, more than one phase can be found in the area. By using this analysis different deformation phases and metamorphic events was determined, showing when the rock was under a certain pressure- 
temperature conditions. The obtained phases show when the deformation phase ended and crystallization of new minerals occurred. Thin section study of rock has been an important source of information in that the deformed rocks are one of the few direct sources of information available for the reconstruction of deformation and metamorphic events. The reconstruction of this study has been made by careful interpretation and analysis of both thin section and field data of the end stage of deformed rock.

From the field observation and thin section analysis at least two phases of metamorphism and five deformation phases are encountered/identified/. They are designated as M1, M2, D1, D2, D3, D4 and D5 (where M and D refer to metamorphic event and deformation phase respectively).

\subsubsection{Deformation History}

The superposed folds in the study area are formed as a result of 3 sets of Deformation. S0 plane was not discernible as it was almost parallel to S1. Throughout this outcrop there is a well-developed gneissosity (marked by the alternation of light and dark color) on the S1 surface. This fabric is associated with the first generation of deformation (D1). Since S1 \& S0 both are parallel in all area except at hinge, F1 is a tight isoclinal Fold formed during D2.

(i). D1, D2 and D3

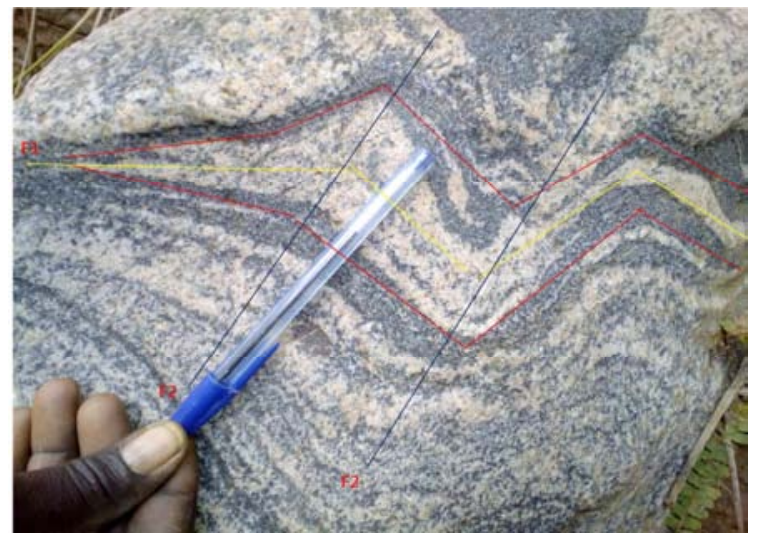

Figure 29. Field photograph from the study Sorobo area documenting 3 sets of deformation phases: Gneissosity (S1) during D1, folding of S1 during D2 and refolding of $S 1$ during $D 3$.

This is a shortening deformation event. Gneissosity (S1) is formed during D1 and the D2 deformation event is characterized by tight to isoclinal folding (F1) of metamorphic segregation layering in the rock unit; F1 folds are recumbent and associated with a prominent axial planar fabric, S1 (Figure 24). S1 is defined by aligning hornblende, feldspar, quartz and +/- mica minerals in the rock unit. Subsequently, the entire ensemble was folded during the D2 deformation along near-vertical axial planes, F2 fold axis are parallel to F1. This upright F2 fold is round hinged, close to open fold. S1-S2 intersection forms a prominent intersection lineation parallel to F2 fold axes. A secondary set of fold which is upright fold may superimpose on an earlier fold which is recumbent fold, resulting in type 3-fold interference patterns which have a parallel fold axis and shows convergent-divergent pattern (Figure 29); this refolding is due to D3. Upright folding (F2) of the S1 foliation during the $\mathrm{D} 2$ deformation is seen in the study area, at times with the development of an axial planar foliation, S2.

(ii). D4-D5

A fourth deformation phase is a shear/strike-slip/ deformation event. D4 deformation phase is formed following the D1-D3 deformation phases, which is characterized by dextral and sinistral strike-slip shearing, affects most lithology of the study area with differing intensity. In the study area the evidence of D4 deformation is in the form of occasional narrow, NNW-SSE trending subvertical shear planes with dextral sense (Figure 31 ). It is also characterized by showing different vergence directions (Figure 15 and Figure 30). This is resulted from sinistral (left-lateral) and dextral (right lateral) shearing. It is inferred to be the result of rotation of pre-existing planar features through the shortening field during progressive dextral and sinistral shearing. In general, both dextral and sinistral shear - sense is recorded in the study area but dextral movement appears dominant. D5 deformation phase is a brittle type of deformation phase, which is formed following D4 shear/strike-slip/ deformation phases and was resulting in different types of faults of varying intensity and orientations (Figure 19).

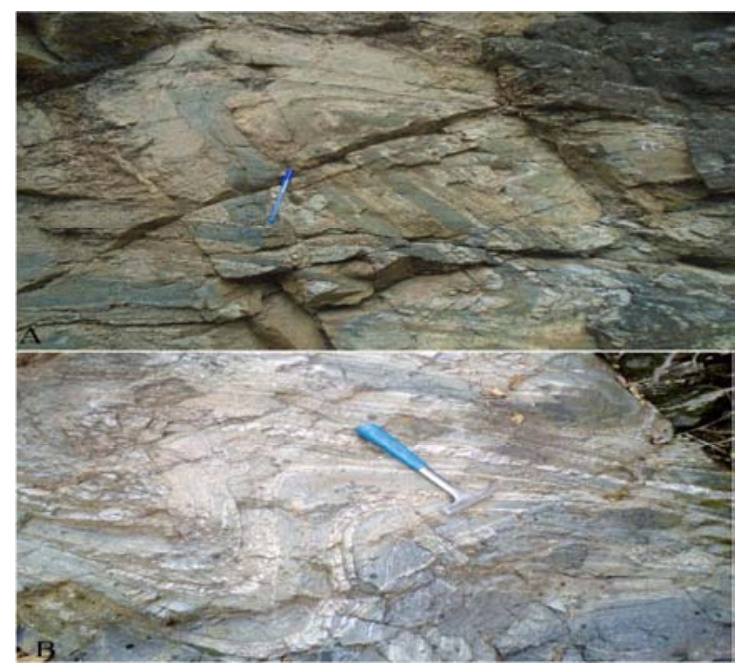

Figure 30. Field photograph shows $N W$-vergence, asymmetric or sinistral (left-lateral) shearing from different area which shows counter-clockwise rotation and resulted during $D 4$.

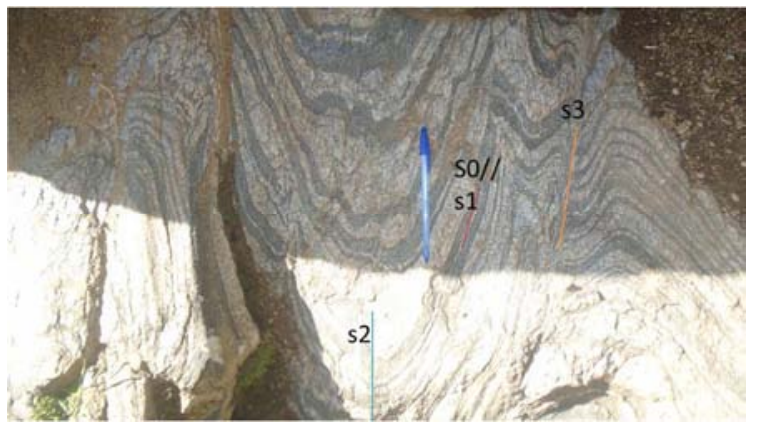

Figure 31. Field photograph indicating foliation series and different sets of deformation phases from D1-D4 in one outcrop. 


\subsubsection{Metamorphic History}

There are two stages of metamorphic events documented in the study area which are designated as M1 and M2. This is done from thin section/petrographic/ analysis of rock samples. M1 lies synchronous with the first phases of deformation (D1) during regional prograde metamorphism and M2 lie in retrograde regional metamorphism mineral assemblages during the late deformation phase (D4) event or shear/strikeslip/ deformation event.

Figure 32A show when plagioclase feldspar alters and produces clay minerals. The feldspar mineral is completely replaced by a new mineral phase, but the area occupied by the clay still has the configuration of the original feldspar crystal. Thus, feldspar is pseudomorphed by clay. Characteristic textures are also generated by pseudomorphic replacement of amphibole mineral to clinopyroxene mineral phases (Figure 32C) caused by reactions involving a hydrous fluid, regular intergrowth from unmixing or exsolution lamellae in pyroxene (Figure $32 \mathrm{D}$ ).
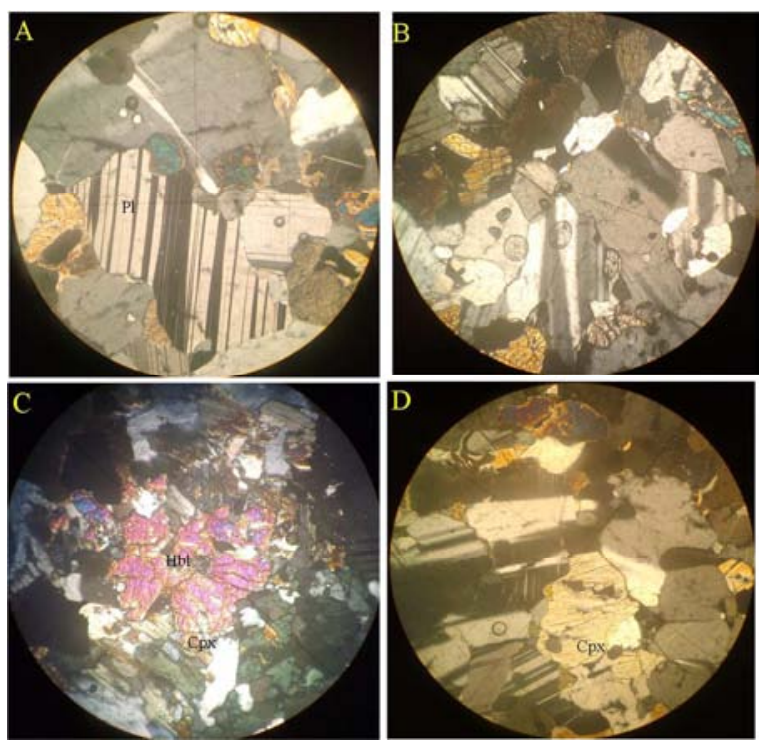

Figure 32. Microphotograph of A) alteration of plagioclase and plagioclase crystal with distinct banding effect of polysynthetic twinning B) fluid inclusion in plagioclase $C$ ) prograde replacement of the amphibole mineral by clinopyroxene and D) exsolution lamellae in clinopyroxene; $10 X, X P L$.

\section{(i). Prograde Metamorphism (M1)}

The metamorphic mineral assemblage in the granulite rock sample is composed of $\mathrm{Cpx}+\mathrm{Pl}+\mathrm{Qtz}+\mathrm{Hbl}+/-\mathrm{Bt}+/-$ opaque minerals (Figure 5); this is a characteristic mineral assemblage of granulite facies. Other rock units are also composed in the same manner but differ in the percentage of major minerals and $+/$ - other accessary minerals. This mineral assemblage also indicates the metamorphic rock contains of igneous protolith. The presence of index mineral garnet also shows the metamorphic peak (M1) of the rock in the study area. The replacement of amphibole mineral by pyroxene in amphibole gneiss rock unit (Figure 32C) is manifested a prograde metamorphism. The metamorphic mineral assemblages of the rock unit are characterized by a mineral that are found in a wide range of temperature and pressure condition. Therefore, the metamorphic rocks of the area have attained granulite facies.

(ii). Retrograde Metamorphism (M2)

This is characterized by a transformation of metamorphic minerals that were stable in the M1 phase of metamorphism to a new metamorphic alteration product /secondary mineral/ under lower P-T condition. From the thin section analysis, the breakdown of biotite to chlorite mineral (Figure 33), and transformation of plagioclase to clay mineral (cloud in thin section) by alteration (Figure 32A) manifested a retrograde metamorphism (M2). The metamorphic mineral assemblage in the amphibolite rock sample is composed of $\mathrm{Hbl}+\mathrm{Pl}+$ Qtz +/- Cpx +/- Bt +/- opaque minerals (Figure 7). The metamorphic mineral assemblages of the rock unit are characterized by a mineral that are found in a medium range of temperature and pressure condition. Therefore, the metamorphic rocks of the area have attained upper amphibolite facies.
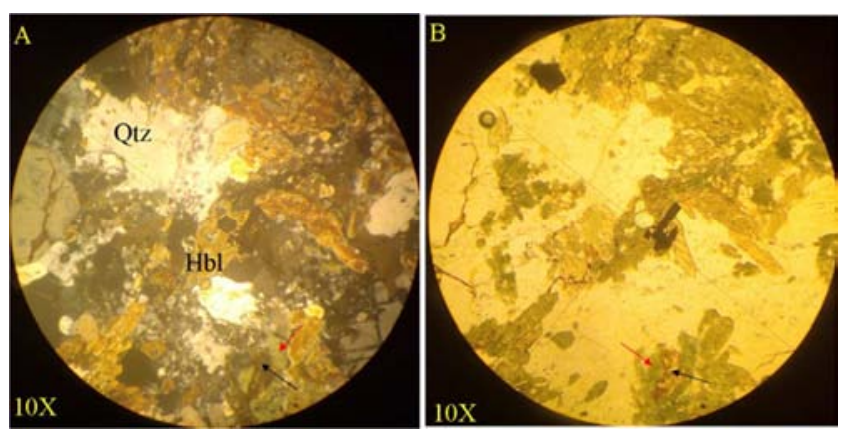

Figure 33. Microphotograph of mineral grain shows Transformation of Bt to Chl by alteration; the breakdown of biotite to chlorite; $A$ and B) shows biotite is going to die out in XPL and PPL respectively. Small residual brownish patches of biotite still occur in PPL (chlorite after biotite); 10X, manifestation of retrogression.

\section{Discussion}

In the study area, the deformation and metamorphic history was investigated by field, microstructural and petrographic analysis. Thin sections of rocks have been an important source of information for this study. Deformed rocks are one of the few direct sources of information available for the reconstruction of tectonic evolution. From field investigation, observations on the geometry of structures should be used to reconstruct the tectonic evolution by correctly interpreting the end stage. From a volume of rock which contains a distribution and orientation of fabric, tectonic evolution of an area was determined. In most deformed rocks in the study area, structures with different style and orientation and minerals which represent different metamorphic grades overprint each other.

Ductile shear sense indicators are also analyzed and interpreted in order to understand the sense of shear/movements/ of blocks. Within the area there are both sinistral/leftlateral/ and dextral/right-lateral/ sense of shearing are identified. This is from both field observation and thin section analysis. The study area is correlated with Hamar domains within omo river project area due to its lithological, 
metamorphic and structural similarities like; strongly and steeply folded, and shows regional NNW-SSE-trending foliation with steep NE dips. One major brittle /fault/ and four ductile deformational phases and two metamorphic events are now recognized in the area based on field observation and thin section analysis. M1 and M2 are designed as 1st and 2nd metamorphic events respectively. D1, D2, D3, D4 and D5 are designed as 1st, 2nd, 3rd, 4th and 5th deformation phases respectively. Retrogression and progression are also associated with deformational phases. An equal-area plot and rose diagram shows the orientation of all fabric, which indicates multiphase deformation. The presence of fold interference pattern resulted from the superposition of later fabric, folding of gneissosity of an earlier fabric, shearing and faulting of an earlier fabric are indications of polyphase deformation in the study Sorobo area.

Granitic magmas are moved through fractures and lineaments and hold important minerals in the study area. Different economic concentrations of minerals were transported and precipitated from hot aqueous solutions through interconnected channel ways (fractures). Therefore, geological structures in the study areas like faults, joints \& fissures, shear zones and folds are important depositional sites for different hydrothermal economic mineral deposits.

Table 1. Summarized characteristics of main deformation events recognized in Sorobo.

\begin{tabular}{ll}
\hline Deformation events & Style \\
\hline D1 & Development of gneissosity (alternating bands of mafic and felsic layers) \\
D2 & Tight to isoclinal, inclined folds, wavelength varies from several centimeter to meter depends on competency of host rocks \\
D3 & Refolding of earlier fold, shows convergent-divergent pattern and have parallel fold axis \\
D4 & Shows different vergence directions resulted from dextral and sinistral shearing \\
D5 & Brittle type (faults) which is displacements of earlier fabric \\
\hline
\end{tabular}

\section{Conclusion}

The study area is found in Konso area, southern Ethiopia within East African Orogeny (EAO) and covered by high grade metamorphic rocks which are exposed mostly along the stream cut. Based on field and thin section study granulite, amphibolite, amphibole gneiss and granitic gneiss rocks are identified. The larger parts of the area are covered by the amphibole gneiss rock unit. There are also different mesoscale geological structures and metamorphic rock fabrics are found.

The study area is affected by different episodes of events like: granitic magma intrusion, metamorphism, folding, fracture (joint) development, fracture filling (veins and veinlet's formation) and displacements of veins by faults and shearing. Five deformation phases and two metamorphic events are recognized from the study area. Development of gneissosity (D1), folding of gneissosity (D2), refolding (D3), east and west shearing (D4)) and faulting (D5) are a major deformation phases of the study the area. There is no isotropic garnet mineral in thin section, but have in the field suggested the metamorphic peak (M1). The peak metamorphic (M1) mineral assemblages are $\mathrm{Cpx}+\mathrm{Pl}+\mathrm{Hbl}$ + Grt and show the characteristic assemblage of granulite facies. The metamorphic mineral assemblage $\mathrm{Hbl}+\mathrm{Pl}+\mathrm{Qtz}$ $+/-\mathrm{Cpx}+/-\mathrm{Bt}$ manifested a retrograde metamorphism (M2) and have attained upper amphibolite facies.

Equal-area projection and rose diagrams were plotted in order to emphasize the distribution of orientation of data. The orientations of different structures from the field and stereonet plots are consistent with the Precambrian metamorphic rock (Mozambique Belt) fabric of southwestern Ethiopia. The randomly distributed data points on great circles on stereoplot of pole to different fabric element are a manifestation of multiphase deformation of the study area.
By analyzing minerals and microstructures from the study area deformation and metamorphic history of an area was determined. Based on field observation and thin section analysis there are two metamorphic events and five deformation phases are identified from the study area. Crosscutting relationship has been used in order to determine the relative ages of different geological structures

\section{Acknowledgements}

I would like to thank Addis Ababa University, School of earth science for adjustment of financial support to do this research successfully. Then I would like to give a special and heartfelt gratitude to Dr. Mulugeta A. for his guiding, advising and supporting and institute of Geological Survey for thin section preparation.

\section{References}

[1] Asrat, A. and Barbey, P. (2003). Petrology, geochronology and $\mathrm{Sr}-\mathrm{Nd}$ isotopic geochemistry of the Konso pluton, southwestern Ethiopia: implications for transition from convergence to extension in the Mozambique Belt, International Journal of Earth science (GeolRundsch), 92, pp. 873-890.

[2] Asrat, A., Gleizes, G., Barbey, P. and Ayalew, D. (2003). Magma emplacement and mafic-felsic magma hybridization: structural evidence from the Pan-African Negash pluton, Northern Ethiopia. J Struct Geol 25, pp. 1451-1469.

[3] Davidson, A. (1983). The Omo River Project, Reconnaissance geology and geochemistry of parts of Ilubabor, Kefa, Gemu Gofa and Sidamo, Ethiopia, Ethiopian Institute of Geological Surveys, Bulletin 2, Addis Ababa, pp. 18-42.

[4] Ethiopian Institute of Geological Survey (EIGS) (2010). Geological Map of Ethiopia, 2nd ed., Unpublished technical report, EIGS, Addis Ababa, Ethiopia, 129 pp. 
[5] Gichile, S. (1992). Granulites in the Precambrian basement of southern Ethiopia: geochemistry, P-T conditions of metamorphism and tectonic setting. J Afr Earth Sci $15 \mathrm{pp}$ 251-263.

[6] Kazmin, V., Shiferaw, A. and Balcha, T. (1978). The Ethiopian basement: stratigraphy and possible manner of evolution. Geologische Rundschau 67, pp. 531-546.

[7] Kroner, A. and Stern, R. J. (2004). Pan-African orogeny, North African Phanerozoic, Rift valley, V 1, PP. 1-3.

[8] Kusky, T. M., Abdelsalam, M., Stern, R. J. and Tucker, R. D. (eds.) (2003). Evolution of the East African and related orogens, and the assembly of Gondwana. Precambrian Res. 123 , pp. $82-85$.

[9] McClay K R (1987). The Mapping of Geological Structures. Department of Geology Royal Holloway and Bedford New College University of London.

[10] Samuel, G. (1991). Structure, metamorphism and tectonic setting of a gneissic terrane, the Sagan Afleta area, southern Ethiopia. Msc thesis, Ottawa-Carleton Geoscience center and University of Ottawa, Canada.
[11] Santosh, M., Morimoto, T. and Tsutsumi, Y. (2006). Geochronology of the khondalite belt of Trivandrum Block, southern India: electron probe ages and implications for Gondwana tectonics. Gondwana Research 9, pp. 261-278.

[12] Shackleton (1979, as cited in Asrat and Barbey, 2003) Petrology, geochronology and Sr-Nd isotopic geochemistry of the Konso pluton, south-western Ethiopia: implications for transition from convergence to extension in the Mozambique belt. Int journal of Earth Science (Geol Rundsch), 92, pp. 873890.

[13] Stern, R. J. (1994). Arc assembly and continental collision in the Neoproterozoic east African Orogen: implications for the consolidation of Gondwanaland. Annu. Rev. Earth Planet. Sci. Lett. 22, pp. 319-351.

[14] Tadesse S., Milesi JP., Deschamps Y (2003). Geology and mineral potential of Ethiopia: a note on geology and mineral map of Ethiopia. Journal of African Earth Sciences. 36 (2003): 273-313.

[15] Vaughan, A. P. M. and Pankhurst, R. J. (2008). Tectonic overview of the West Gondwana margin. Gondwana Research, 13, pp. 150-162. 